\title{
em torno do conceito de metáfora de jakobson e lacan
}

\author{
Gelson Santana
}

Pós-graduando em lmagem e Som na ECA-USP

"A metáfora é o rabalho de sonho da linguagem."

DONALD DAVIDSON

\begin{abstract}
This paper considers Jean-François Lyotard's vision about the differences between Roman Jakobson c Jaques Lacan concepts of mctaphor and melonim.
\end{abstract}

KEY WORDS: Mctaphor - Mctonim - Similarity - Contiguity Sintagm - Paradigm.

O presente trabalho resulta da leitura dos textos: "Dois aspectos da linguagem e dois tipos de afasia". de Roman Jakobson (1975), c "L"instance de la lettre dans l'inconscient ou la raison depuis Freud" de Jacques Lacan (1966), cm comparação com a leitura que deles faz Jcan-François Lyotard, em Discours, Figure (1985, p. 250-60).

A primcira preocupação foi o acompanhamento do texto de Jakobson através de suas conexões com Saussure, sua implicação a outras artes que não a verbal. De maneira sucinta, foi ainda feita uma abordagem da teoria dos eixos em seu relacionamento com a teoria dos sonhos de Freud. 


\section{em torno do conceito de metáfora de jakobson e lacan}

Desse ponto, surgiu a necessidade de leitura do texto lacaniano, tendo em vista a divergência entre Lacan e Jakobson no que diz respeito à condensação na metáfora.

Segundo Saussure, "num estado de lingua tudo se baseia em relações" (SAUSSURE, 1975, p. 142). Os cixos sobre os quais giram tais relações da categoria lingüistica são dois e foram primeiramente abordados em teoria por N. Kruszewski, tcórico polonês da linguagem:

"Cada palavra está ligada por dois gêneros de elos: primeiro, por inumeráveis elos da similaridade com palavras aparentadas pelos sons, pela estrutura e pela significação e segundo, por outros tantos elos de contigïidade com diversas maneiras de falar; uma palavrá sempre um membro de familias ou de sistemas determinados de palavras e simulianeamente um membro de séries sintáticas determinadas de palavras" (HOLENSTEIN, 1978, p. 143).

Retomando tais formas de grupamento lingüistico, Saussure introduz modificações, especialmente no que concerne à limitação da caracterização associativa ao eixo paradigmático. Para Saussure, o primeiro eixo, que ele denomina sintagmático, determina a posição e a função de un termo em todos os enunciados possiveis. O segundo, que ele chama de associativo e Hjelmslev de paradigmático, prevê o termo ligado a outros que podem substituí-lo.

Os dois eixos são ligados à teoria da significação como valor, em Saussure; por sua vez, a última está ligada ao fato de que a linguagem remete a um sistema fechado: a língua. Como sistema fechado, a lingua pode falar sobre seu objeto, que lhe é exterior. Assim, tal fechamento permite juntar duas funções: a dupla função interna (sintagma/paradigma) e a função externa (referência). A essa duplicidade relativa do termo na língua corresponde uma duplicidade de operação na fala.

Jakobson propõe representar essa duplicidade na fala da seguinte 


\section{Gelson Santana}

maneira: o falante seleciona cada termo entre todos aqueles que a ele estão ligados por possibilidades de substituição (paradigmáticas) e combina os termos selecionados de acordo com as relações de associação (sintagmática) que governam o encadeamento de cada termo empregado. Assim, para Jakobson, a relação de paradigma (no falante) corresponde a um ato de combinação. A partir dessa colocação, Jakobson aponta dois tipos de afasia. Quando a doença atinge a capacidade seletora, perturba a similaridade. $\mathrm{O}$ afásico, sofrendo dessa incapacidade, perde a possibilidade da substituição:

"O afäsico que sofre de distúrbio da fuinção de substitui-
fão não completará o gesto do observador - de indicação
ou manipulação - com o nome do objeto indicado. Em vez
de dizer 'isso é chamado lápis' acrescentará simplesmen-
te uma observação eliptica acerca do seu uso: 'Para
escrever"..(JAKOBSON,1975, p. 45).

A perda da capacidade de substituição implica a impossibilidade de uso de sinônimos, de tradução de uma outra lingua ou de outro sistema de signos e até na impossibilidade de repetir simplesmente uma palavra. Holenstein observa que tal tipo de doença,
"ao estimulo 'champanhe' não reage com respostas tais como: 'Você está falando do vinho branco espumante da França' (circunlocuçâo) ou: 'Entendi você está pensando no champanho" (pleonasmo). "(HOLENSTEIN, 1978, p. 147).

O afásico desse tipo emprega palavras mais gerais ou apenas expressões restritas a um contexto concreto específico. No caso da palavra "champanhe" cle escolherá metonimicamente alguma coisa que tenha relação (espacial, temporal ou causal) com ela.

A deterioração da capacidade de construir proposições ou, em termos mais gerais, de combinar entidade lingüisticas mais simples em unidades mais complexas está, na realidade, limitada a um só tipo de afasia, 
que é o oposto "do tipo discuitido no capitulo anterior" (JAKOBSON, 1975, p. 50).

Este é o segundo tipo de afasia estudado por Jakobson: O distúrbio da contigüidade. Neste tipo de afasia, "deficiente quanto ao texto (...) a extensão e a variedade das frases diminuem" (JAKOBSON, 1975, p.50). O afásico assim afetado é incapaz de formar frases coerentes. Perde o uso das palavras relacionais (HOLENSTEIN, 1978, p. 148).

\begin{abstract}
"Quanto menos uma palavra depender gramaticalmente do contexto, tanto mais forte será sua persistência no discurso dos afásicos com distírbio da fiunção de contigüidade. e tanto mais rapidamente será eliminada pelos pacientes que sofrem de distúrbios da similaridade" (JAKOBSON, 1975, p. 51).
\end{abstract}

A normalidade do discurso se apóia na combinação equilibrada dos eixos. Dessa forma, é o equilíbrio entre eles que garante a comunicabilidade.

Sem dúvida que o problema da comunicabilidade pode estar vinculado a um outro tipo de discurso desequilibrado, porém não necessariamente afásico. Trata-se do discurso literário, ao qual Jakobson aplicou sua teoria de similaridade/contigüidade. Para os lingüístas, o discurso literário tem, justamente, a característica básica de desequilibrar a linguagem "normal".

\footnotetext{
"Manipulando esses dois tipos de conexão (similaridade e contigüidade) em seus dois aspectos (posicional e semântico) - por seleção, combinação e hierarquização um individuo revela seu estilo pessoal, seus gostos e preferências verbais" (JAKOBSON, 1975, p. 56).
}

Jakobson elabora uma classificação sobre três estágios diferentes do discurso: retórica, gêneros e escolas vinculando-os aos dois eixos relacionais: paradigma e sintagma. Assim: 


\section{Gelson Santana}

\begin{tabular}{|l|l|l|}
\hline $\begin{array}{c}\text { Natureza das relaçōes } \\
\text { entre os termos }\end{array}$ & $\begin{array}{c}\text { Relações } \\
\text { paradigmáticas }\end{array}$ & $\begin{array}{c}\text { Relaçóes } \\
\text { sintagmáticas }\end{array}$ \\
\hline Lingua & similaridade & contigüidade \\
Fala & seleção & combinação \\
Tropo & metáora & metonimia \\
Gêncro & poesia & prosá \\
Escola & romantismo & realismo \\
& simbolismo & \\
\hline
\end{tabular}

O quadro acima resume as considerações de Jakobson, toda a parte $V$ - Os polos metafóricos c metonímicos de seu estudo acerca da afasia. Os critérios por ele usados não extrapolam o terreno da linguagem articulada propriamente dita. No entanto, Jakobson deixa claro que

"a predominância alternativa de um ou outro desses dois processos não é de modo algum exchusivo da arte verbal. A mesma oscilação aparece em outros sistemas de significação que não a linguagem "(JAKOBSON, 1975, p. 57).

Dessa maneira, ele estende a metáfora e metonimia, tropos vinculados às relações paradigmáticas e sintagmáticas ("A metạ́fora é incompativel como disturbio da similaridade e a metonimia com o disturbio da contigüidade"(JAKOBSON, 1975, p. 55) a outras artes que não a literária.

\section{“(...) pode-se notar a orientação manifestadamente} metonimica do Cubismo, que transforma o objeto numa série de sinédoques; os pintores surrealistas reagiram com uma concepção visivelmente metafórica. A partir das produções de D. W. Griffith, a arte do cinema, com sua capacidade al.tamente desenvolvida de variar o ângulo, a perspectiva e o foco das tomadas, rompeu com a tradição do teatro e empregou uma gama sem precedentes de grandes planos sinedóquicos e de montagens metonimicas em ge- 
ral. Em filmes, como os de Charlie Chaplin e Eisenstein. esses procedimentos foram suplantados por um novo tipo melafórico de montagem. com suas 'fusões superpostas - verdadeiras comparações filmicas." (JAKOBSON, 1975, p. 58).

Jakobson estende a idćia de competição entre os dois procedimentos. metonimico e metaforico, a "todo processo simbolico. quer seja subjetivo quer social" (JAKOBSON, 1975, p. 61). Isso o leva a abordar a estrutura dos sonhos:

"Eis porque numa investigação da esmutura dos sonhos. a questão decisiva é saber se os simbolos e as sequiencias temporais usadas baseiam-se na contigiuidade ( transferéncia' metonimica e 'condensação' sinedríquica de Freud) ou na similaridade ("identificação 'e simbolismos. fieudianos)(JAKOBSON,1975,p.61).

Se observarmos, ele coloca o deslocamento frcudiano ( a transferência metonímica) e a condensação freudiana ( a sinédoque) na coluna das relações sintagmáticas ( vide quadro acima). Enquanto a identificação e o simbolismo ficarão na coluna correspondente ao paradigma. Tal procedimento não se coaduna com o de Lacan, que identifica a condensação com metáfora c o deslocamento com metonimia.

É quanto à condensação que Lacan c Jakobson diferem. Em psicanálise, Lacan
"modificou a proposição de Jakohson e coordenou ambos" os eixos com os dois principais mecanismos que Freud atribuin ao inconsciente " (HOLENSTEIN, 1978, p. 153).

Dessa forma, a condensação fica vinculada ao eixo metafórico; e deslocamento, ao cixo metonimico. 


\section{Gelson Santana}

Vẹjamos a posição lacaniana acerca da condensação:

"A Verdichtung, condensação é a estrutura de sobreimposição dos significantes em que toma seu campo a metáfora. e cujo nome por condensar em si mesmo a Dichtung. indica a co-naturalidade do mecanismo com a poesia até o ponto em que aquele envolve a finçäa proprianente tradicional desta" (LACAN, 1966, p. 511).

Assim. segundo Lacan, a metáfora é "uma palavra pela outra". nesse conceito de "estrutura de sohreimposição de significantes". Ele cita o célebre exemplo de Victor Hugo: "Sa gerhe n'éteait pas avare ni haineuse" (Seu feixe não era avaro nem sentia ódio).

Ai. a palavra "feixe" substitui o nome próprio Booz.

Porém, não existem apenas as vias metafóricas, mas também vias metonimicas da condensação. Como quando $\mathrm{em}$ um sonho a figura de uma animal substitui a de um ser humano. mas vem trajada com as roupas ( metoninia) deste último. Assim também ocorrem deslocamentos metafóricos no sonho ou na arte. Por exemplo. quando um dedo arrancado a alguém simboliza adultério. Isso foi demonstrado por Freud em diversos casos em seus cstudos sobre o trabalho dos sonhos.

Quanto a Jakobson, este parte de uma noção de substituição que se fundamenta sobre um conceito cstritamente estruturalista da lingua $\mathrm{c}$ depois passa a uma accpção retórica da metáfora que se aplica ao discurso.

Falando do verso de Victor Hugo que exemplifica como modelo da metáfora, Lacan diz que:

"(...) a chispa criadora da metáfora não brota da colocação presenie de chras imagens. ou seja de dois significantes igualmente atualizados. Brota entre dois significantes dos quais um substitui o outro tomando seu lugar na cadeia 


\section{em torno do conceito de metáfora de jakobson e lacan}

significante, o significante oculto segue presente por sua conexão (metonimica) com o resto da cadeia" (LACAN, 1966, p. 507).

Ou scja, o "feixc" substitui Booz. Entre os dois significantes surge a chispa da metáfora. ' Mas, para Jakobson. o verso em questão não seria jamais metafórico. Embora a concepção do processo metafórico no texto sobre a afasia se bascic na reação substituitiva. Enquanto o processo metonimico se bascia na reação predicativa. Estudando a posição de Jakobson, Lyotard excmplifica:

"Em um teste de associação. propõe-se como indutor a uma criança a palavra choupana: se a resposta é do tipo: queimou ou é uma casinha pobre. a reação é dita predicativa: se a resposta é do tipo: choupana, cabana, palácio, a reação é dita substituitiva" (LYOTARD.1985, p. 2.55$)$.

O caráter da resposta predicativa é o de constituir uma frase. Mas se pode observar que há dois tipos de frase: "choupana queimou " c "choupana é uma casinha pobre". Na primeira, temos uma frase narrativa, mas na segunda não. Embora a organização sẹja sintagmática pela posição (sujeito e predicado) cxiste a possibilidade semântica da substituição, pois: "ć uma casinha pobre " pode substituir: "choupana".

Segundo Lyotard, Roman Jakobson distingue, então, um aspecto posicional ( no enunciado) e um aspecto semântico ( no quadro de significações do contexto, dentro da língua). Uma metáfora, então, pode ocupar posição predicativa e ser, semânticamente, substituitiva.

1. Se "BOoz endorm". mesmo que alusivamente (GRINAUD, 1978, p. 104), funciona como exemplo de um corpus lacaniano é porgue a criaçāo artistica é tomada como um sintoma em yte \& preciso que se husque a palavra de ordem (segredo de bdipoe da psicanálise) que nos fura os ollos. Esse segredo toma-se "visivel" a partir do momento que cm Lacan o significado de Jakobson se transforma ou se desloca em sujeito. Fazendo da teoria da metáfora uma teoria da metáfora do sujeito. 


\section{Gelson Santana}

"Um enunciado como seu feixe não era avaro nem sentia ódio não pode. de mancira al guma passar por uma me'taforca cos ol hos de Jakohson: näo apenas seus termos formam um enunciado de tipo evidentemente predicadivo, mas ainda. sobre o plano semântico. eles são insubstituiveis." (LYOTARD.1985. p. 255)

Aos olhos de Jakobson. portanto. "l'u feixe não era avaro nem sentia odic $"$. será tomado como metonimia. uma vez que feixe pode ser visto como emblema de Booz. Para Lyotard. “(...) o use de imperféte (era) dá ao enunciado uma conolação tipicamente narrativa" (LYOTARD.1985. p. 256).

Na metáfora poćtica. o que interessa. além disso. não ć apenas aquilo que Lacan² deixa claro cm sua definição desse $\operatorname{tr}(0)$ (). Ao pocta interessa que a substituição nunca é aquela autorizada pelo uso. Pclo contrário: o uso faria com que a subtituição não passasse de uma mera escolha. uma espécic de sobrecarga da significação, em que um termo estaria de modo sobredeterminado em detrimento de outros. Por exemplo: "Ele se chateia - ou se aborrece - ou se entedia - neste hugar". Isso ć apenas uma questão de estilo. como diz LYOTARD (1985).

A verdadcira metáfora poctica joga com a transgressão no campo das substituiçòes. Desafia o uso ( sobre o qual se fundamenta a substituição) c o transforma.

Assim. André Breton se posicionava: "Para mim. a imagem surrealista mais forte é aquela que apresenta o mais alto gran de arbi"raricdade" (BRETON.1990). p. 50).

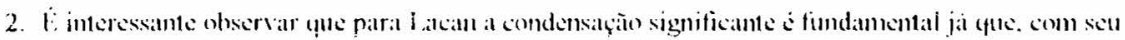

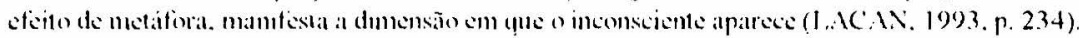

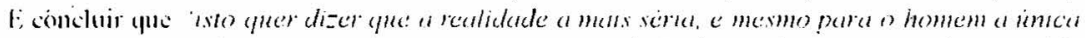

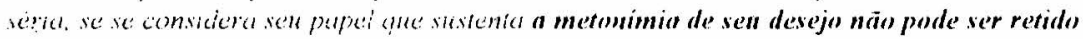

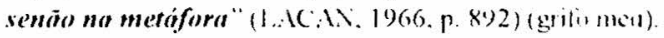


em torno do conceito de metáfora de jakobson e lacan

\section{Bibliografia}

BRETON. André. (1990). Manifestes du surréalisme. Paris, Gallimard.

GRIMAUD. Michel. (1978). Sur une metaphore metonsmique hugolienne sclon Jacques Lacan. Littérature.(29) fev.

HOLENSTEIN. Elmar. (1978). Introdução ao pensamento de Roman Jakobson. Rio de Janciro. Zahar.

JAKOBSON. Roman. (1975). Dois aspectos da linguagem e dois tipos de afasia. In: Lingüiistica e comunicação. São Paulo, Cultrix.

LACAN, Jacques. (1966). L'instance de la lettre dans l'inconscient ou la raison depuis Freud. In: Licrits. Paris. Seuil.

__.(1993). O seminário: livro 11 .2ed. Rio de Janciro, Jorge Zahar.

LYOTARD, J.F. (1985). Le travail de rêve ne pense pas. In: 1)iscours. figure. 4ed. Paris, Klincksieck.

TOLEDO, Dionisio (org.). (1978). Circulo lingizistico de Praga: estruuralismo e semiologia. Porto Alcgre; Globo.

SAUSSURE. Ferdinand de. (1975). Curso de lingiiistica geral. 7ed. São Paulo, Cultrix. 